\title{
Glycopattern analysis and structure of the egg extra-cellular matrix in the Apennine yellow-bellied toad, Bombina pachypus (Anura: Bombinatoridae)
}

\author{
Giovanni Scillitani ${ }^{1}$, Angela Maria Moramarco ${ }^{2}$, Roberta Rossi ${ }^{3}$, \\ Maria Mastrodonato ${ }^{1}$
}

\author{
${ }^{1}$ Department of Biology, Laboratory of Histology and Comparative Anatomy, "Aldo Moro" \\ University of Bari, Italy \\ ${ }^{2}$ Department of Animal Production, "Aldo Moro" University of Bari, Italy \\ 3Department of Pathologic Anatomy, Laboratory of Ultrastructural Pathology, "Aldo Moro" \\ University of Bari, Italy
}

\begin{abstract}
We studied the glycopatterns and ultrastructure of the extra-cellular matrix (ECM) of the egg of the Apennine yellow-bellied toad Bombina pachypus, by light and electron microscopy in order to determine structure, chemical composition and function. Histochemical techniques in light microscopy included PAS and Alcian Blue $\mathrm{pH} 2.5$ and 1.0, performed also after $\beta$-elimination. Lectin-binding was tested with nine lectins (AAA, ConA, DBA, HPA, LTA, PNA, SBA, UEA-I, WGA). An inner fertilization envelope (FE) and five jelly layers $\left(\mathrm{J}_{1}-\mathrm{J}_{5}\right)$ were observed, differing in histochemical staining, lectin binding and ultrastructure. Most glycans were O-linked, with many glucosamylated and fucosylated residues. The fertilization envelope presented a perivitelline space and a fertilization layer, with mostly neutral glycans. The jelly layers consisted of fibers and granules, whose number and orientation differed between layers. Fibers were densely packed in $\mathrm{J}_{1}$ and $\mathrm{J}_{4}$ layers, whereas a looser arrangement was observed in the other layers. Jelly-layer glycans were mostly acidic and particularly abundant in the $\mathrm{J}_{1}$ and $\mathrm{J}_{4}$ layers. In the $\mathrm{J}_{1}, \mathrm{~J}_{2}$ and $\mathrm{J}_{5}$ layers, neutral, $\mathrm{N}$-linked glycans were also observed. Mannosylated and/or glucosylated as well as galactosyl/galactosaminylated residues were more abundant in the outer layers. Many microorganisms were observed in the $\mathrm{J}_{5}$ layer. We believe that, apart from their functions in the fertilization process, acidic and fucosylated glycans could act as a barrier against pathogen penetration. (Folia Histochemica et Cytobiologica 2011; Vol. 49, No. 2, pp. 306-316)
\end{abstract}

Key words: amphibia, Bombina pachypus, egg jelly, lectin, electron microscopy

\section{Introduction}

Amphibian eggs are surrounded by an extra-cellular matrix (ECM) consisting of an inner vitelline envelope and an outer jelly coat, made up of layers whose number and composition are species-specific

Correspondence address: G. Scillitani, Laboratorio di

Istologia e Anatomia comparata,

Dipartimento di Biologia,

Università degli studi di Bari Aldo Moro,

via Orabona 4/a, I-70125 Bari, Italy;

tel./fax: (+ 39 80) 54433 49;

e-mail: g.scillitani@biologia.uniba.it
[1-3]. The jelly coat layers consist mainly of glycoproteins and glycosaminoglycans [3-5], and their carbohydrate-chain composition has been investigated in a number of species [6-9]. In general, the glycans are O-linked to the core proteins and several sequences are unique to a given species [5-11]. In most studies, the whole jelly coat is taken for biochemical analysis, without distinguishing between the layers or the sublayers. Histochemical studies have demonstrated that the distribution of neutral and acidic carbohydrates varies among the layers in several species $[1,4,12]$. Lectin-binding experiments on jelly coat layers have revealed heterogeneity in the distribution of binding sites among 
and within layers $[5,13,14]$. Electron-microscopy studies have revealed that each layer presents a unique fiber and glycoprotein composition, and that the jelly coats are complex structures in which globular glycoproteins are bound to a fibrous glycoproteic superstructure $[5,15]$.

Jelly coat layers have been found to be involved in a number of functions, such as interactions with spermatozoa in fertilization [16, 17], mechanical support, spacing and substrate attachment for the egg clusters [18], hosting for oxygen-supplying, symbiote algae [19], and protection against predators, pathogens, environmental stressors, and contaminants [3, 20,21]. Amphibians with a more complex jelly coat covering show a higher resistance to water molds [22]. The penetration of contaminants is significantly reduced and/or slowed by jelly coat layers [21, 23], even if this is not always observed $[24,25]$. The resistance of egg ECM to environmental stresses can even vary geographically within a single species [26]. Several papers have attempted to link the presence of particular molecules in the ECM to given functions [e.g. 5, 8, 10, 11, 13, 16, 27]. A relatively small number of species has been investigated taking into account the huge diversity of ECM organization among living amphibians $[1,3,18]$, and the role of several jelly molecules is still poorly understood [27].

Knowledge about the structure and composition of the egg jelly coat is fundamental to understanding both the fertilization processes and the mechanisms by which contaminants, e.g. pesticides and pathogens, e.g. Saprolegniacee, affect egg survival and the consequent reproductive success of amphibian species, the prevalence of many of which is declining around the world $[28,29]$.

With all this in mind, in the present paper we studied, using different staining and microscopic observation techniques, the composition and organization of ECM in the Apennine yellow-bellied toad, Bombina pachypus.

Our goals were as follows:

1. To link the structure and glycopattern composition of such a complex structure;

2. To give some functional interpretations of the findings in the light of the available literature;

3. To obtain preliminary data in understanding the role of ECM in the protection of the egg, and its implications for future studies about the effects of contaminants on the survival of eggs in this endemic, but declining, species [30];

4. To contribute to the understanding of ECM diversity among anurans.

\section{Material and methods}

Egg collection. Eggs of the Apennine yellow-bellied toad, Bombina pachypus, were collected from fields in the Gravine of Laterza (Taranto, Apulia, Italy) in April 2008 soon after their deposition. No more than one pair of eggs was taken from each clutch, usually consisting of 15-20 eggs, to avoid hampering reproductive success. This egg collection was authorized by Italy's Ministero dell'Ambiente.

Light microscopy. The eggs were embedded in a Technovit 8100 kit (EMS, Hatfield, PA, USA). The eggs were fixed in a $4 \%$ paraformaldehyde solution in $0.1 \mathrm{M}$ phosphatebuffered-saline (PBS) pH 7.4 at $4^{\circ} \mathrm{C}$ for three hours. After several rinses in PBS, pieces were incubated overnight, at $4^{\circ} \mathrm{C}$, in PBS with $6.8 \%$ added sucrose, and then dehydrated with increasing acetone, also at $4^{\circ} \mathrm{C}$. Infiltration was performed by incubating the specimens in a Technovit 8100 monomer for six hours at $4^{\circ} \mathrm{C}$ with gentle stirring. Finally, the eggs were embedded with an ice-cold solution of 15:1 infiltrating solution. Polymerization was carried out on an ice bed for three hours. Semi-thin sections ( $2 \mu \mathrm{m}$ thick $)$ were cut with glass knives using an LKB Ultratome and mounted on microscope slides, coated with polylysine (Sigma, St. Louis, MO, USA). Semi-thin sections were incubated for five minutes at $37^{\circ} \mathrm{C}$ in $0.01 \%$ trypsin (Sigma) and $0.1 \%$ $\mathrm{CaCl}_{2}$ in PBS, $\mathrm{pH} 7.8$ before staining.

Histochemistry. The sections were stained with periodic acid-Schiff (PAS) hemallum [31] for general carbohydrate staining, and Alcian-Blue (AB) at $\mathrm{pH} 2.5$ or $\mathrm{pH} 1.0$ to detect acidic carbohydrates. All the cited reagents were from Sigma. PAS and Alcian stainings were also combined to differentiate between neutral and acidic carbohydrates in the same section [32]. PAS-AB pH 2.5 were also performed after $\beta$-elimination, a method that removes the O-linked oligosaccharides from glycoproteins [33]; prior to staining, sections were incubated with $0.2 \mathrm{M} \mathrm{KOH}$ in dimethylsulphoxide $\mathrm{H}_{2} \mathrm{O}$ - ethanol (50:40:10) for one hour at $45^{\circ} \mathrm{C}$, followed by neutralisation with $10 \mathrm{mM} \mathrm{HCl}$ and washing in PBS pH 7.4.

Lectin histochemistry. The binding of nine lectins (all from Sigma except for AAA from Vector Laboratories, Burlingame, CA, USA) was assessed to determine the nature and distribution of glycosidic residues in the egg layers. Lectins were labelled with horseradish peroxidase (HRP), fluoresceine isothiocyanate (FITC) or phosphatase. The lectins, their concentrations, and their sugar specificities are summarized in Table 1. References for the lectins are given in References 34-42.

For the binding with FITC-conjugated lectins (ConA, DBA, HPA, PNA, LTA, WGA, UEA-I), the sections were incubated for 30 minutes in blocking buffer, i.e. $1 \%$ normal 
Table 1. Characteristics of the lectins utilized

\begin{tabular}{|l|l|c|c|c|}
\hline Lectin & $\begin{array}{l}\text { Source and } \\
\text { reference numbers }\end{array}$ & Binding specificity & $\begin{array}{c}\text { Lectin } \\
\text { concentration } \\
\text { [mg/ml] }\end{array}$ & $\begin{array}{c}\text { Inhibitory } \\
\text { sugar }\end{array}$ \\
\hline Con A & Canavalia ensiformis [34] & D-mannose, D-Glucose & 0.005 & $0.1 \mathrm{M} \mathrm{M} \alpha \mathrm{M}$ \\
\hline WGA & Triticum vulgaris [35] & (GlcNAc $\beta 1,4) \mathrm{n}$ & 0.02 & $0.01 \mathrm{M}$ TACT \\
\hline SBA & Glycine max [36] & GalNAc & 0.02 & $0.2 \mathrm{M} \mathrm{GalNAc}$ \\
\hline HPA & Helix pomatia [37] & GalNAc & 0.02 & $0.2 \mathrm{M} \mathrm{GalNAc}$ \\
\hline DBA & Dolichos biflorus [38] & $\alpha$-GalNAc & 0.02 & $0.2 \mathrm{M} \mathrm{GalNAc}$ \\
\hline PNA & Arachis hypogaea [39] & Gal $\beta 1,3$ GalNAc & 0.01 & $0.2 \mathrm{M} \mathrm{Gal}$ \\
\hline AAA & Aleuria aurantia [40] & Fuc $\alpha(1,6)$ GlcNAc- $\beta$ NAsn Fuc $\alpha(1,3)$, Fuc $\alpha(1,4)$ & 0.01 & $0.2 \mathrm{M} \mathrm{L-Fuc}$ \\
\hline UEA-I & Ulex europaeus [41] & Fuc $\alpha(1,2)$ & 0.01 & $0.2 \mathrm{M} \mathrm{L-Fuc}$ \\
\hline LTA & Tetragonolobus purpureus [42] & $\begin{array}{c}\text { L-Fuc } \alpha 1,6 \mathrm{GlcN} \text {-Fc } \\
\text { and L-Fuc } \alpha 1,2 \text { Gal } \beta 1,4[\mathrm{~L}-F u c 1,3] \text { GlcNAcb1,6R }\end{array}$ & 0.02 & $0.2 \mathrm{M} \mathrm{L-Fuc}$ \\
\hline
\end{tabular}

Fuc — fucose; Gal — galactose; GalNAc - N-acetylgalactosamine; GlcNAc — N-acetylglucosamine; M $\alpha \mathrm{M}$ - methyl- $\alpha$-mannopyranoside; TACT - N,N',N"-triacetylchitotriose

goat serum in $0.1 \mathrm{M}$ Tris-buffered saline $\mathrm{pH} 7.4$ (TBS) and then incubated for one hour at room temperature with the FITC-lectin solution in TBS. Sections were subsequently rinsed in the same buffer and mounted in $70 \%$ glycerin in TBS. For the binding with HRP-conjugated SBA lectin, the sections were exposed to $3 \%$ hydrogen peroxide for ten minutes to inhibit endogenous peroxidase activity, and then incubated for 60 minutes at room temperature with HRP-lectin in TBS. HRP activity was then visualised with $0.005 \%$ 3-3'-diaminobenzidine (DAB: Sigma)-0.01\% hydrogen peroxide in $0.05 \mathrm{M}$ TBS [43] for ten minutes in the dark at room temperature. Finally, the sections were dehydrated through a graded ethanol series, cleared in Histolemon (Carlo Erba, Rodano, Milan, Italy), and mounted in DPX (Fluka BioChemika, Steinheim, Germany).

For the binding with AAA phosphate-conjugated lectin, the sections were incubated for one hour at room temperature with the lectin solution in TBS. Sections were subsequently rinsed in the same buffer and incubated in the substrate working solution (BCIP/NBT alkaline phosphatase substrate Kit IV from Vector Laboratories, Burlingame, CA, USA) for 15 minutes at room temperature. The endogenous alkaline phosphatase activity was inhibited by adding levamisole to the working solution. After washing in $0.1 \mathrm{M}$ TBS pH 9.5 for five minutes, the sections were counterstained with methyl green (Sigma) dehydrated, cleared and mounted following the HRP-lectin protocol.

Two different controls for lectin labeling were used: 1) substitution of the respective lectin with TBS alone; and 2) incubation in the lectin with the addition of the appropriate inhibitory sugar (concentrations are set out in Table 1). Positive controls were included from different regions of the digestive system from two amphibians, Bufo balearicus (formerly known as Bufo viridis) and Triturus carnifex, whose mucins are known to bind to the tested lectins [44, 45].
Transmission electron microscopy. The eggs were fixed in $4 \%$ glutaraldehyde and processed for embedding in Epoxy Resin-Araldite (M) CY212 (TAAB, Aldermaston, UK) as previously reported [46]. Semi-thin sections $2 \mu \mathrm{m}$ thick were stained with Toluidine blue-PAS (PAS-TB). Ultra-thin sections were mounted on formwar-coated nickel grids and stained routinely with uranyl acetate and lead citrate [47]. Images were captured using a Nikon Eclipse 600 photomicroscope equipped with a Nikon DMX 1200 camera (Nikon Instruments SpA, Calenzano, Florence, Italy).

Each experiment was repeated twice on specimens taken from three different eggs, giving a total of six repetitions. Staining/labeling in each experiment was assessed by at least two independent observers and scored as positive $(+)$, moderately positive $(-+)$, or negative $(-)$ according to their intensity.

\section{Results}

Freshly-collected eggs of $B$. pachypus were surrounded by an ECM about 3-4 mm thick. Embedding reduced the ECM thickness because of dehydration. Staining techniques revealed an inner fertilization envelope (FE), and a jelly coat subdivided into five main layers, called $\mathrm{J}_{1}-\mathrm{J}_{5}$, with $\mathrm{J}_{1}$ being the innermost.

\section{Histochemistry}

Table 2 summarizes the histochemical staining patterns observed. Figures $1 \mathrm{~A}$ and $1 \mathrm{~B}$ show the ECM stained by PAS combined with AB ph 2.5 and pH 1.0, respectively. The FE is weakly PAS-positive and negative with $\mathrm{AB}$ at both $\mathrm{pH} 2.5$ and 1.0. PAS-positivity of $\mathrm{FE}$ increases towards the $\mathrm{J}_{1}$ layer, where a more intensely stained sublayer is observed. The $\mathrm{J}_{1}$ layer 
Table 2. Histochemical stainings of the egg extra-cellular matrix of Bombina pachypus

\begin{tabular}{|l|c|c|c|c|}
\hline \multirow{2}{*}{ Layer } & \multicolumn{4}{|c|}{ Staining } \\
\cline { 2 - 5 } & PAS & AB pH 2.5 & AB pH 1.0 & $\begin{array}{c}\beta \text {-elimination } \\
\text { PAS AB pH 2.5 }\end{array}$ \\
\hline $\mathrm{FE}$ & $+-++^{1}$ & -- & -- & -- \\
\hline $\mathrm{J}_{1}$ & ++ & ++ & ++ & Red \\
\hline $\mathrm{J}_{2}$ & +- & +- & +- & -- \\
\hline $\mathrm{J}_{3}$ & -- & ++ & ++ & -- \\
\hline $\mathrm{J}_{4}$ & ++ & $+-1+++^{2}$ & +- & Red \\
\hline $\mathrm{J}_{5}$ & ++ & +- & +- & Red \\
\hline
\end{tabular}

Layers: FE - fertilization envelope; $\mathrm{J}_{1}-\mathrm{J}_{5}$ - jelly coat layers; ${ }^{1} \mathrm{PAS}$-positivity increases in a sublayer at the boundary with $\mathrm{J}_{1}$;

${ }^{2}$ Alcianophily increases in a sublayer at the boundary with $\mathrm{J}_{5}$

Table 3. Lectin binding of the egg extra-cellular matrix of Bombina pachypus

\begin{tabular}{|c|c|c|c|c|c|c|c|c|c|}
\hline \multirow{2}{*}{ Layer } & \multicolumn{7}{|c|}{ Lectin } \\
\cline { 2 - 11 } & Con A & WGA & SBA & HPA & DBA & PNA & AAA & UEA-I & LTA \\
\hline $\mathrm{FE}$ & -- & +- & -- & +- & -- & ++ & +- & -- & -- \\
\hline $\mathrm{J}_{1}$ & +- & ++ & +- & -- & -- & -- & ++ & -- & +- \\
\hline $\mathrm{J}_{2}$ & -- & ++ & -- & -- & -- & -- & +- & -- & -- \\
\hline $\mathrm{J}_{3}$ & +- & ++ & -- & ++ & -- & -- & +- & -- & -- \\
\hline $\mathrm{J}_{4}$ & ++ & ++ & -- & ++ & +- & ++ & ++ & -- & +- \\
\hline $\mathrm{J}_{5}$ & ++ & ++ & -- & -- & +- & ++ & +- & +- & +- \\
\hline
\end{tabular}

Layers: FE - fertilization envelope; $\mathrm{J}_{1}-\mathrm{J}_{5}-$ jelly coat layers

stains deep blue with combined PAS-AB pH 2.5, whereas it stains violet with PAS-AB pH 1.0, suggesting that PAS-positivity is masked by intense alcianophily with PAS-AB pH 2.5. The $\mathrm{J}_{2}$ layer is made up of a network of fibers and granules positive to PAS and $\mathrm{AB}$ stainings. The $\mathrm{J}_{3}$ layer stains mostly blue at both PAS-AB pH 2.5 and PAS-AB pH 1.0. The $\mathrm{J}_{4}$ layer is positive to PAS and weakly positive to the AB stainings, with a stronger alcianophilic sublayer at the transition zone with the $\mathrm{J}_{5}$ layer. The latter has a 'foamy' appearance and hosts several microorganisms, with fibers and granules positive to $\mathrm{PAS}$ and/or to $\mathrm{AB}$ stainings. After $\beta$-elimination, only the $\mathrm{J}_{1}, \mathrm{~J}_{4}$ and $\mathrm{J}_{5}$ layers keep their PAS-positivity, but not their alcianophily, whereas the other layers are not stained or weakly stained (Figure 1C).

\section{Lectin histochemistry}

Table 3 sets out the lectin-binding patterns observed. Figures 1D-L show the binding patterns of each lectin. Of the nine lectins tested, AAA (Figure 1D) and WGA (Figure 1H) bind to both the FE and all the jelly layers, whereas the others show selectivity towards one or more layers. Each layer binds to at least three different lectins. In general, the $\mathrm{J}_{1}, \mathrm{~J}_{4}$ and $\mathrm{J}_{5}$ layers bind to a higher number of lectins than $\mathrm{J}_{2}$ and $\mathrm{J}_{3}$, even if it is not always easy to state the positivity of layers with a loose texture, like $\mathrm{J}_{2}, \mathrm{~J}_{3}$, and $\mathrm{J}_{5}$. PNA (Figure 1J) and DBA (Figure 1K) bind mostly to the outer jelly layers. UEA-I binds weakly only to the $\mathrm{J}_{5}$ layer (Figure 1E). No labeling was observed in control sections exposed to $\mathrm{DAB}-\mathrm{H}_{2} \mathrm{O}_{2}$ medium after substitution of TBS for lectin or incubated with the corresponding hapten sugars (Figure 1G).

\section{Transmission electron microscopy}

The FE shows two areas, the innermost being less electron-dense than the outer (Figure 2A). In the inner area, sparse granules are observed, whereas in the outer there is a loose mesh of fibers with no clear orientation. In the jelly envelope, each of the five layers observed in light microscopy presents a peculiar structure. $\mathrm{J}_{1}$ is made up of densely-packed fibers running parallel to the egg's surface (Figures 2A, B). Fibers with the same orientation of $\mathrm{J}_{1}$ are also seen in the $\mathrm{J}_{2}$ layer, but they are more loosely arranged and present a series of granules (Figure $2 \mathrm{~B}$ ). In the $\mathrm{J}_{3}$ layer, the number of fibers decreases and their orientation is less 


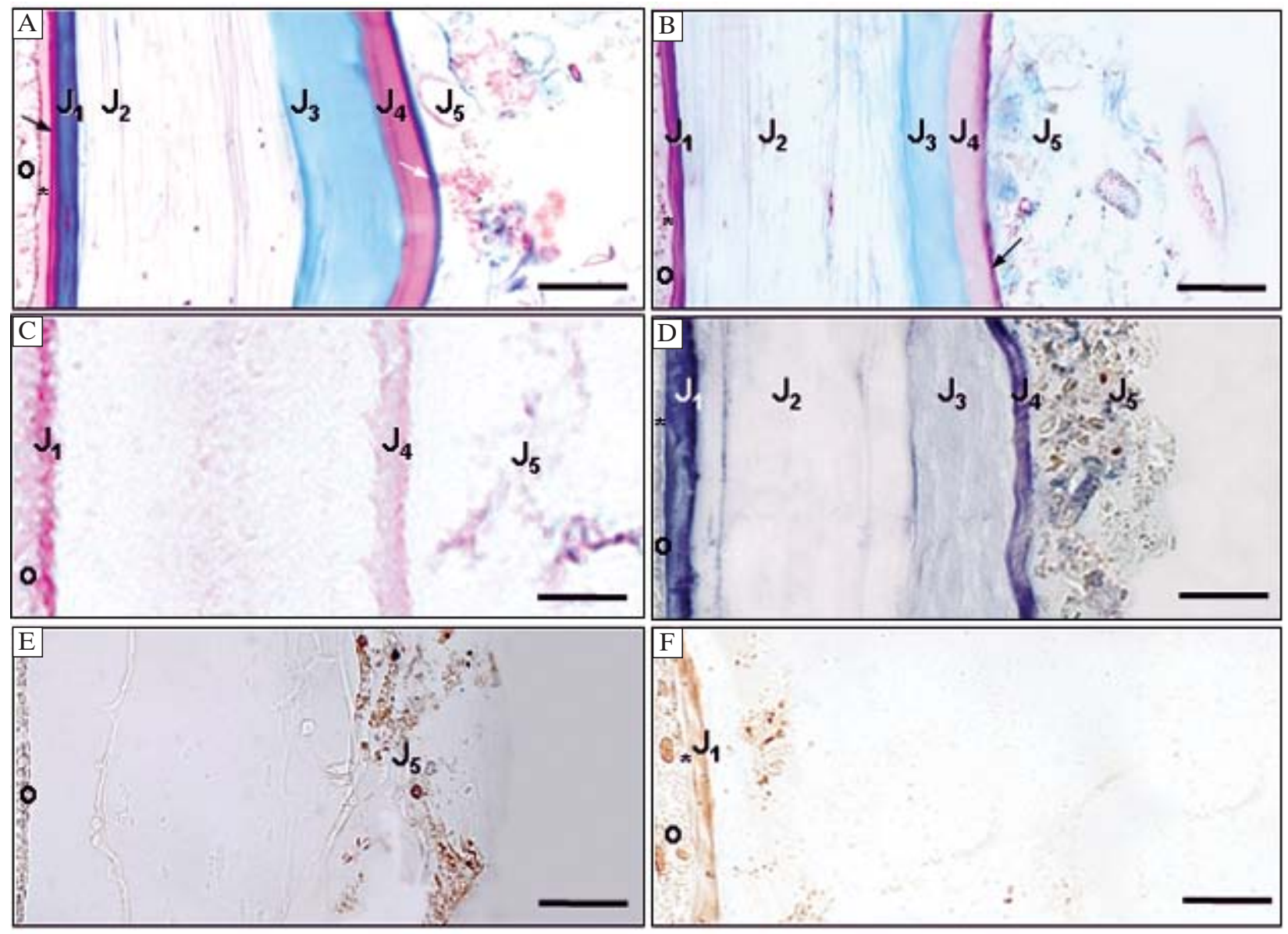

Figure 1. Egg extra-cellular matrix of Bombina pachypus. A. PAS-Alcian Blue $\mathrm{pH}$ 2.5. Layers $\mathrm{J}_{1} \mathrm{~J}_{3}$ and a sublayer between $\mathrm{J}_{4}$ and $\mathrm{J}_{5}$ (white arrow) are intensely alcianophilic. An intensely PAS-positive area is seen in the fertilization envelope (*) towards $\mathrm{J}_{1}$ (black arrow). $\mathrm{J}_{1},-\mathrm{J}_{5}$ - jelly coat layers 1 to 5; o, egg. B. PAS-Alcian Blue $\mathrm{pH} 1.0$. $\mathrm{J}_{3}$ is still markedly alcianophilic. The sublayer between $\mathrm{J}_{4}$ and $\mathrm{J}_{5}$ is still evident. $\mathrm{J}_{1},-\mathrm{J}_{5}-$ jelly coat layers 1 to 5 ; o, egg; * - fertilization envelope. C. PAS-Alcian Blue pH 2.5 after b-elimination. PAS-positivity persists in $\mathrm{J}_{1}, \mathrm{~J}_{4}$ and $\mathrm{J}_{5}$ layers, whereas alcianophily is suppressed. $\mathrm{J}_{1},-\mathrm{J}_{5}$ - jelly coat layers 1 to 5; o, egg. D. Binding with AAA lectin (phosphatase-conjugated). $\mathrm{J}_{1}$ and $\mathrm{J}_{4}$ are intensely stained. Several microorganisms can be seen in $\mathrm{J}_{5}$ layer. $\mathrm{J}_{1},-\mathrm{J}_{5}$ - jelly coat layers 1 to 5 ; o, egg; * - fertilization envelope. E. Binding with UEA-I lectin (peroxidase-conjugated). Moderate binding can be seen only in $\mathrm{J}_{5}$ layer. $\mathrm{J}_{5}-$ jelly coat layer 5; o, egg. F. Binding with SBA lectin (peroxidase-conjugated). Moderate binding can be seen only in the $\mathrm{J}_{1}$ layer. $\mathrm{J}_{1}$ — jelly coat layer 1 ; o, egg; * — fertilization envelope

clear, whereas the granular component is more abundant (Figures 2C, D). Densely-packed fibers are again visible in the $\mathrm{J}_{4}$ layer, the organization of which looks similar to the $\mathrm{J}_{1}$ layer (Figures $2 \mathrm{D}, \mathrm{E}$ ). The $\mathrm{J}_{5}$ layer is characterized by several granules and a loose network of fibers, hosting several microorganisms (Figures 2 E, F). It was not possible to observe the two sublayers revealed by histochemical techniques at the $\mathrm{FE} / \mathrm{J}_{1}$ and $\mathrm{J}_{4} / \mathrm{J}_{5}$ boundaries, respectively: in these areas, the layers trespass one into another rather abruptly, with no particular structural organizations suggesting the existence of the cited sublayers (Figures 2A, E).

\section{Discussion}

By combining histochemical and lectin-histochemical techniques in light microscopy and electron mi- croscopy, we showed that the extra-cellular matrix of the egg of $B$. pachypus is a complex structure with an envelope and five jelly layers, each characterized by a specific structure and carbohydrate composition.

Lectin-binding patterns do not suggest the presence of a monosaccharide in a glycan, but rather of an oligomer in which a specific monosaccharide is probably present. In any case, lectin-histochemistry is very useful in comparing structures and detecting variations between different layers of the egg envelope [5, 13, 14].

The fertilization envelope, the innermost layer of the ECM, is made up of two zones with different textures, the inner comprising sparse granules and the outer comprising a loose mesh of fibers. The inner and outer zones should correspond to the perivitelline space and the fertilization layer, respectively, observed in Xenopus laevis [48]. Glycoconjugates in the FE are 


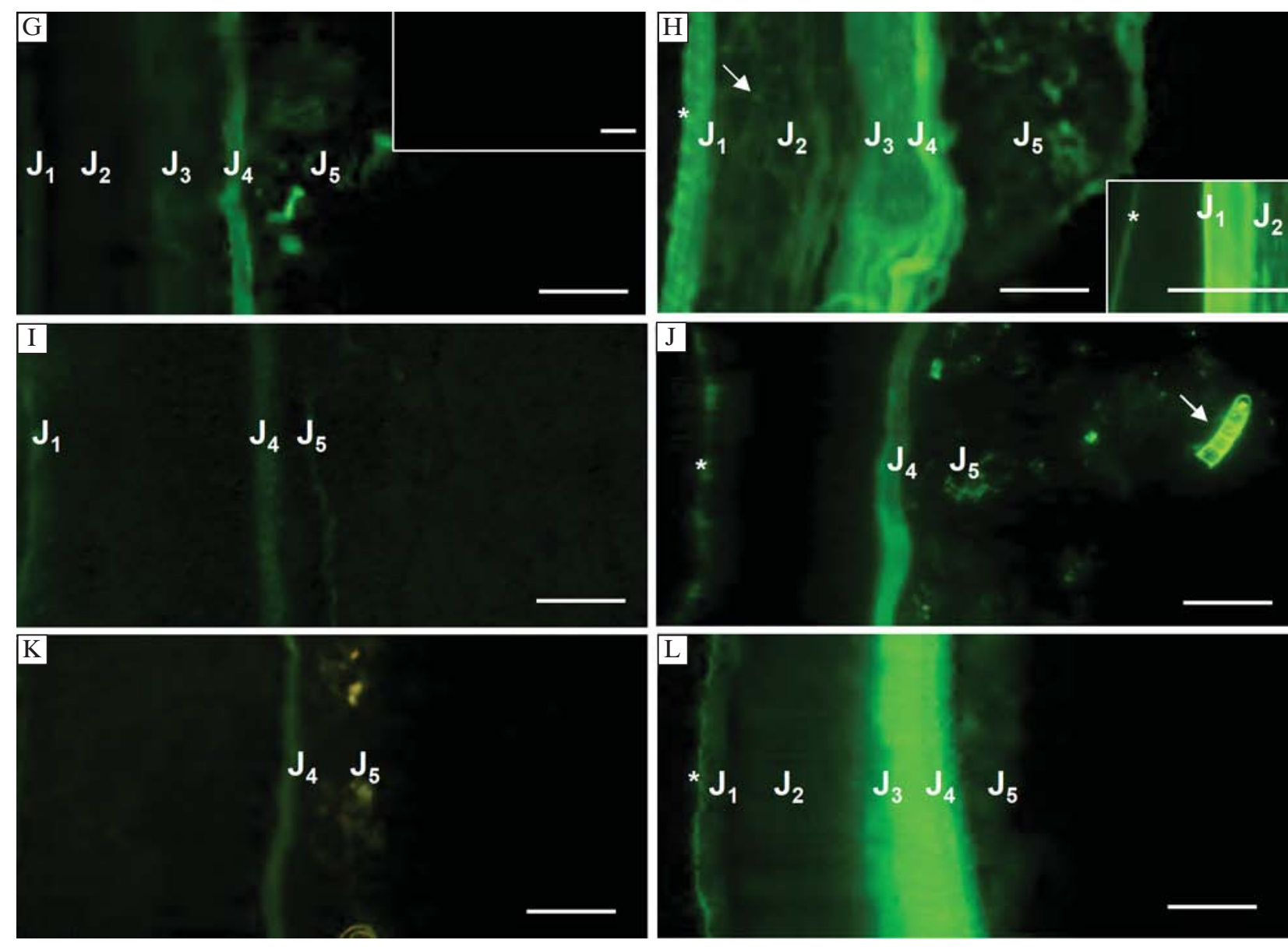

Figure 1 - continued. G. Binding with ConA lectin (FITC-conjugated). Binding is seen mostly in $\mathrm{J}_{4}$ and $\mathrm{J}_{5}$ layers. Insert: negative control. $\mathrm{J}_{1},-\mathrm{J}_{5}$ - jelly coat layers 1 to 5 . H. Binding with WGA lectin (FITC-conjugated). The lectin binds to all layers. In the $\mathrm{J}_{2}$ layer lectin binds to both fibers and granules (white arrow). Insert: section with partial detachment of $\mathrm{J}_{1}$ to show lectin binding to the fertilization envelope $(*) . \mathrm{J}_{1},-\mathrm{J}_{5}$ - jelly coat layers 1 to $5 ; *$ — fertilization envelope. I. Binding with LTA lectin (FITC-conjugated). The lectin binds to $\mathrm{J}_{1} \mathrm{~J}_{4}$ and $\mathrm{J}_{5}$ layers. $\mathrm{J}_{1},-\mathrm{J}_{5}-$ jelly coat layers 1 to 5 ; * - fertilization envelope. J. Binding with PNA lectin (FITC-conjugated). Binding is mainly observed to the fertilization envelope, $\mathrm{J}_{4}$ and $\mathrm{J}_{5}$. White arrow indicates a fragment of a filamentous green alga. $\mathrm{J}_{1},-\mathrm{J}_{5}-$ jelly coat layers 1 to 5 ; * - fertilization envelope. K. Binding with DBA lectin (FITC-conjugated). $\mathrm{J}_{4}$ and $\mathrm{J}_{5}$ layers bind to the lectin. $\mathrm{J}_{4}$, - jelly coat layer 4; $\mathrm{J}_{5}$ - jelly coat layer 5. L. Binding with HPA lectin (FITC-conjugated). Main binding is seen to the fertilization envelope, $\mathrm{J}_{3}$ and $\mathrm{J}_{4}$ layers. $\mathrm{J}_{1},-\mathrm{J}_{5}-$ jelly coat layers 1 to 5 ; $^{*}-$ fertilization envelope. Scale bar $=50 \mu \mathrm{m}$

mostly neutral and O-linked, presenting galactosyl/ galactosaminylated, glucosaminylated and fucosylated residues. Towards the $\mathrm{J}_{1}$ layer, a zone that stains more intensely can be seen; boundary zones like these should be referred to as 'membranes' [3] and it is unclear whether they are actual, distinct structures or simply optical representations of transition between two layers that have different densities. The lack of differences in lectin binding or structure of this membrane in respect to the $\mathrm{FE}$ or the $\mathrm{J}_{1}$ layer does not support the existence of a true layer between them.

The $\mathrm{J}_{1}$ layer of $B$. pachypus consists of a number of densely-packed fibers running parallel to the egg's surface. It is rich in acidic oligosaccharidic residues, as demonstrated by its intense staining with $\mathrm{AB} p H$ 2.5. Reduction of alcianophily with $\mathrm{AB}$ pH 1.0 suggests that the acidic residues are mostly sialylated, whereas its suppression after $\beta$-elimination indicates that such residues are $\mathrm{O}$-linked. By contrast, the persistence of PAS-positivity after $\beta$-elimination indicates the presence of neutral, N-linked glycans. Besides, lectin-binding experiments indicate the presence of mannosylated and/or glucosylated, galactosaminylated, and fucosylated residues. WGA-binding could be explained by either the presence of N-acetylglucosamine or Neu5Ac sialic acid.

The $\mathrm{J}_{2}$ layer has a loose structure, with fibers arranged in a parallel orientation similar to $\mathrm{J}_{1}$ and granules. Neutral and acidic, mostly O-linked glycans are present, with $\mathrm{N}$-acetylglucosamine and fucose residues in the oligosaccharidic chains.

The $\mathrm{J}_{3}$ layer present a fibrous structure like the previous layers, but the fibers are more spaced, with a less clear orientation and an increased number of 

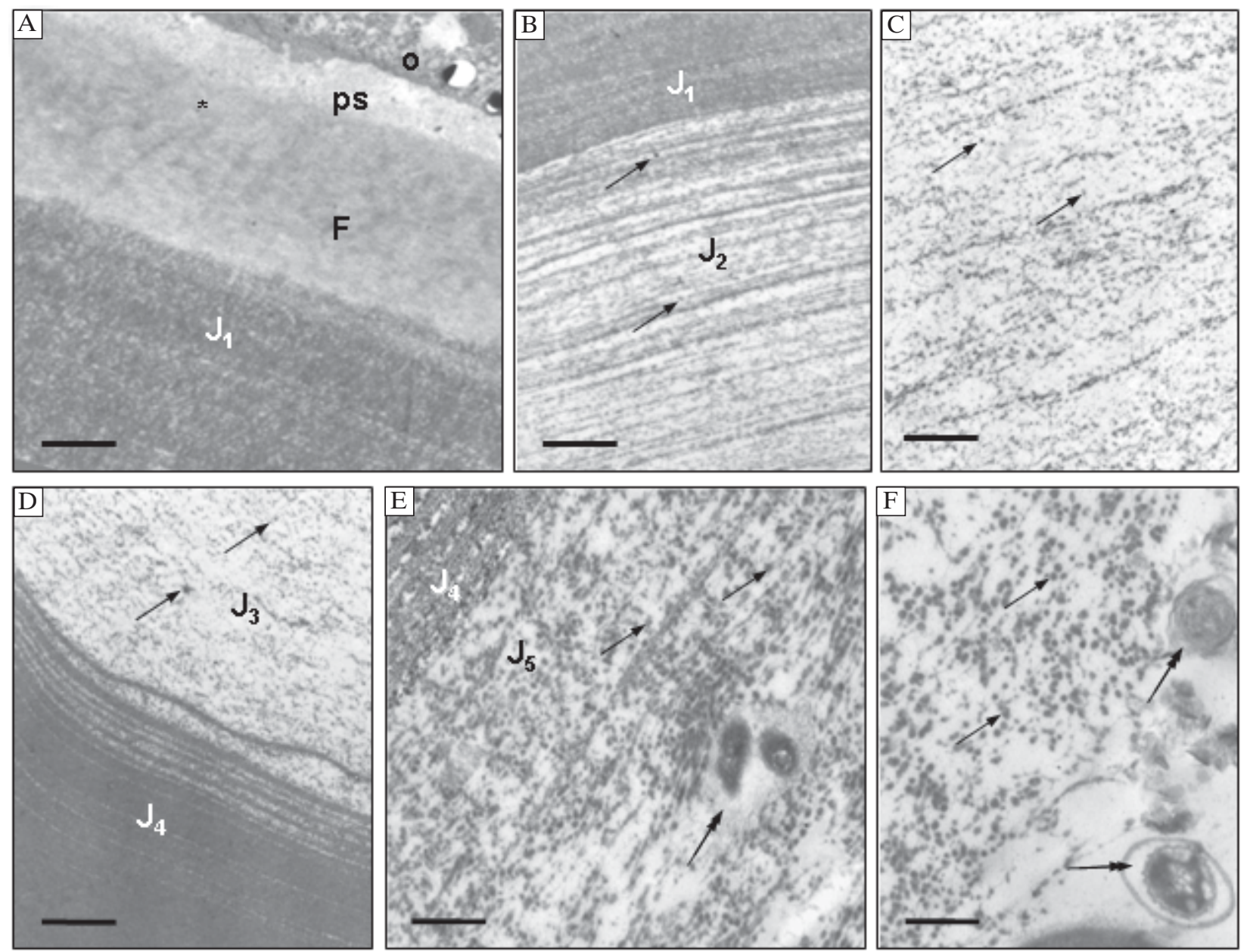

Figure 2. Ultrastructure of egg extra-cellular matrix of Bombina pachypus in transmitted electron microscopy. A. Fertilization envelope $(*)$ showing the perivitelline space (ps) next to the egg (o) and the fertilization layer $(F)$, and $\mathbf{J}_{1}$ layer with densely fibrous packing. Scale bar $=1.4 \mu \mathrm{m}$. B. $\mathrm{J}_{1}$ (upper) and $\mathrm{J}_{2}$ (lower) layers, with the latter having a looser arrangement of fibers and granules (arrows). Scale bar $=1.8 \mu \mathrm{m}$. C. $\mathrm{J}_{3}$ layer with granules (arrows) along fibers. Scale bar $=1.8 \mu \mathrm{m}$. D. $\mathrm{J}_{3}$ (upper right) and $\mathrm{J}_{4}$ (lower left) layers, the fibers of the latter being densely packed. Arrows indicate granules in the $\mathrm{J}_{3}$ layer. Scale bar $=1.8 \mu \mathrm{m}$. E. Transition between $\mathrm{J}_{4}$ and $\mathrm{J}_{5}$ layers, with a reduced number of fibers and an increased number of granules (simple arrows) in the latter. The double arrow indicates a microorganism, possibly a blue alga. Scale bar $=0.7 \mu \mathrm{m}$. F. Detail of $\mathrm{J}_{5}$ layer with granules (simple arrows) and two microorganisms (double arrows). Scale bar $=0.45 \mu \mathrm{m}$

granules. It stains blue with both $\mathrm{AB} \mathrm{pH} 2.5$ and $\mathrm{AB}$ $\mathrm{pH} 1.0$, and is PAS-negative, whereas $\beta$-elimination suppresses alcianophily. These results suggest that the fibers contain proteoglycans with carboxylated and sulfated glycosaminoglycans O-linked to the core protein, since both proteoglycans and glycosaminoglycans are scarcely, or not at all, PAS-positive [49]. Residues of mannose and/or glucose, $\mathrm{N}$-acetylglucosamine, $\mathrm{N}$-acetylgalactosamine and fucose are probably present in the oligosaccharidic chains.

Similar to $\mathrm{J}_{1}$, the $\mathrm{J}_{4}$ layer has densely-packed fibers. These are PAS-positive and weakly alcianophilic with $\mathrm{AB} \mathrm{pH} 2.5$. The suppression of alcianophily with $\mathrm{AB} \mathrm{pH} 1.0$ and $\beta$-elimination indicate the presence of carboxylated, O-linked oligosaccharidic chains.
Several lectins bind to this layer, suggesting the presence of mannosylated, glucosyl/glucosaminylated, galactosyl/galactosaminylated and fucosylated residues. Similar to that observed at the FE/ $\mathrm{J}_{1}$ boundary, a 'membrane' can be seen between $\mathrm{J}_{4}$ and $\mathrm{J}_{5}$ intensely stained with PAS-AB pH 2.5 and PAS-AB pH 1.0, but the lack of distinctive ultrastructural and lectin-binding features in respect of the bordering layers suggests that this membrane is merely an optical transition between the layers.

The $\mathbf{J}_{5}$ layer appears foamy in light microscopy, being made up of a very loose network of fibers and granules. The $\mathrm{J}_{5}$ layer is involved in the spacing and adhesion of the eggs among them and to the substrate. Neutral and acidic glycans, both $\mathrm{O}$ - and $\mathrm{N}$-linked, are 
present, with residues of mannose and/or glucose, galactose, $\mathrm{N}$-acetyl-glucosamine, $\mathrm{N}$-acetyl-galactosamine, and fucose. Several microorganisms found at this level can sometimes confuse the interpretation of lectin-binding to the $\mathrm{J}_{5}$ layer because they are coated with autogenous mucins.

In the jelly envelopes of the species Bombina bombina and $B$. variegata (B. pachypus is sometimes included in the latter species [50]), 28 O-linked carbohydrate chains have been identified [7]. The species have very similar glycans, sharing the sequences $\operatorname{GlcNAc}(\beta 1-3)[\operatorname{Fuc}(\alpha 1-4)] \operatorname{GlcNAc}(\beta 1-6)$ and $\operatorname{GlcNAc}(\alpha 1-4) \operatorname{Gal}(\beta 1-4) \operatorname{Gal}(\beta 1-3)$, and fucosylated residues are linked mostly in $(1,4)$ to proximal $\mathrm{N}$-acetylglucosamine or in $(1,2)$ to galactose [7]. The presence of similar residues in $B$. pachypus can be inferred from our lectin-binding experiments, but we cannot compare the results for each single layer with those from $B$. bombina and $B$. variegata, because their jelly envelopes were analyzed as a whole, without distinction between layers [7].

The fertilization layer in the FE of B. pachypus differs from that of $X$. laevis in lacking both a clear parallel orientation of the fibers and a more electrondense $\mathrm{F}_{c}$ layer [48]. The latter is apparently also missing from the $\mathrm{FE}$ of other species [4, 51]. It is unclear whether this layer is really missing in B. pachypus or was not revealed by our techniques. The filamentous structures in the FE are interpreted as aggregates of ZP glycoproteins [17]. In Xenopus laevis, these present mostly N-linked, neutral glycans [52]. Reduction of PAS-positivity after $\beta$-elimination suggests that in $B$. pachypus O-linked glycans are also present, even if is not possible to state whether they are attached to glycoproteins of the ZP family. An O-linked, galactosaminylated residual is also found in a Xenopus laevis ZP [17].

Similar to B. pachypus $\mathrm{J}_{1}$, a strongly acidic layer adjacent to the FE is found in a number of species $[4,12,53-55]$ and contains both carboxylated and sulfated glycoconjugates. Carboxylated glycans probably include sialic acid, as suggested by positivity to WGA lectin, which is involved in several functions, such as viscosity of the layer, three-dimensional conformational stability, protection from attack and degradation, hydration, osmotic regulation as well as sperm interaction [56-58]. Sulfated glycans can have functions similar to the sialylated (and, possibly, be present in the same chains [59]), and are known to inhibit polyspermy, whereas neutral glycans select sperms for penetration [8]. The presence of $\mathrm{N}$-linked glycans suggests a structural role in keeping the three-dimensional organization of the layer and, possibly, the correct orientation of regulatory mole- cules [59]. This is supported by the presence of fucosylated residues, suggesting the existence of a fucan fibrous superstructure to which globular glycoproteins are bound [5, 60]. Fucosylated residues can also act in reducing bacterial motility [61]. Mannosylated residues can be present in the core of the Nlinked glycans [59]. The corresponding layer of $\mathrm{Xe}$ nopus laevis resembles that of $B$. pachypus in having a fibrous structure and binding sites for WGA and ConA [5, 13, 17].

Further comparisons between our results and those of previous workers on other species are very difficult because of differences in the number of layers, techniques, interpretations, and terminology $[3,4]$.

In the $\mathrm{J}_{2}$ layer of $B$. pachypus, the loose structure and the presence of mostly O-linked, acidic chains suggest a prevailing function in osmoregulation, hydration and spacing. Similar to $\mathrm{J}_{1}$, WGA-binding could be explained by sialic acid and fucosylated residues could act against pathogens.

The $\mathrm{J}_{3}$ layer is rich in proteoglycans, glycosaminoglycans and granules, probably made by globular glycoproteins. The highly acidic residues are probably involved in the same functions hypothesized for the previous layers; in particular, the relatively larger spaces among fibers can be important in terms of storing water and diffusible molecules, like sperm chemoattractants. Galactosaminyl and glucosaminyl residues found in $\mathrm{J}_{3}$ layer can be explained by the presence of glycosaminoglycans [59].

The structure of the $\mathrm{J}_{4}$ layer is similar to that of $\mathrm{J}_{1}$, and carboxylated, mannosylated, galactosaminylated, glucosaminylated and fucosylated residues are also present. Thus, this layer could have functions similar to that of $\mathrm{J}_{1} . \mathrm{J}_{4}$ differs from $\mathrm{J}_{1}$ in having galactosylated residues and in lacking sulfated and N-linked oligosaccharides. Galactose could be associated with $\mathrm{N}$-acetylglucosamine in lactosamine structures that are common in O-linked glycan chains [62]. Polylactosamine chains, usually fucosylated or sialylated, can be involved in water retention, the presentation of glycan for interaction with lectin-like receptors, and in mucin/microorganism interactions [59].

$\mathbf{J}_{5}$ is the outermost jelly coat and is probably involved in the adhesion and spacing between eggs, as well as in storing diffusible molecules involved in fertilization, something that has been observed in other species [14, 27, 63-65]. Its structural functions are suggested by the presence of $\mathrm{N}$-linked glycans and mannosylated residues that can form the core of these glycans, as observed in the $\mathrm{J}_{1}$ layer. Another important function of the $\mathrm{J}_{5}$ layer is in interacting with the microorganisms coating the egg. It is unclear whether these organisms are epibionts, symbionts or patho- 
gens. Oxygen supply and protection from excessive lighting functions have been proposed for several algae, some of which are even exclusive to amphibian egg jelly layers $[3,18]$, whereas a number of bacteria and molds feed on jelly layers and/or eggs and embryos [28]. Since microorganisms are found in $\mathrm{B}$. pachypus $\mathrm{J}_{5}$ layer, but not in the inner ones, it is probable that the mucins of the inner layers act as a barrier against them, as previously observed.

The previous functional interpretations are to be regarded as a preliminary attempt to link glycopatterns and structures; the functions proposed for a given layer can be shared with other ones. For example, fucosylated residues are present in all layers, so that structural and antibacterial functions could be suggested for each of them. Furthermore, functions of the same residues can differ between layers: acidic glycans can play a more important role in sperm interactions in the outer layers [8], whereas they could have a prevailing function in hydrosaline and acidic homeostasis in the inner ones.

B. pachypus presents a relatively high number of jelly layers in respect of other anurans $[1,3]$. The number of layers itself can be linked to an increased protection against pathogens, since species with thicker jelly-coated eggs are less exposed to water mold infection than species with thinner coats [22]. Nonetheless, the jelly coat is not a sufficient barrier against penetration by herbicides like isoproturon [24], or insecticides like $\alpha$-cypermethrin and endosulfan $[25,66]$, although it seems to reduce penetration by polycyclic aromatic hydrocarbons [21] and 2,4-D butoxyethyl ester [23], even though it is supposed that eggs of species with different jelly-coat thickness should differ in resistance to chemical penetration [21].

In conclusion, our study confirms the complex organization of the extracellular matrix of the amphibian egg and its species-specificity that can be fully understood only by integrating data from multiple approaches. Further studies are needed to fully understand the role of glycans in functions such as protection from pathogens and possible hosting for oxygen-supplying algae, as well as the effects of pollutants on their structure, and thus possible alterations of their protective functions.

\section{References}

1. Salthe SN. The egg capsules in the Amphibia. J Morphol. 1963;113:161-71.

2. Coppin A, Maes E, Strecker G. Species-specificity of amphibia carbohydrate chains: the Bufo viridis case study. Carbohydr Res. 2002;337:121-132.

3. Altig R, McDiarmid RW. Morphological diversity and evolution of egg and clutch structure in amphibians. Herpetol Monographs. 2007;21:1-32.
4. Carroll Jr EJ, Wei SH, Nagel GM, Ruibal R. Structure and macromolecular composition of the egg and embryo jelly coats of the Anuran Lepidobatrachus laevis. Develop Growth Differ. 1991;33:37-43.

5. Bonnell BS and Chandler DE. Egg jelly layers of Xenopus laevis are unique in ultrastructure and sugar distribution. Mol Reprod Dev. 1998;44:212-220.

6. Delplace F, Maes E, Lemoine J, Strecker G. Species specificity of O-linked carbohydrate chains of the oviducal mucins in amphibians: structural analysis of neutral oligosaccharide alditols released by reductive beta-elimination from the eggjelly coats of Rana clamitans. Biochem J. 2002;363:4557-4571.

7. Coppin A, Florea D, Maes E, Cogálniceanu D, Strecker G. Comparative study of carbohydrate chains released from the oviducal mucins of the two very closely related amphibian species Bombina bombina and Bombina variegata. Biochimie. 2003;85:53-64.

8. Zhang J, Xie Y, Hedrick JL, Lebrilla CB. Profiling the morphological distribution of O-linked oligosaccharides. Anal Biochem. 2004:334:20-35.

9. Florea D, Maes E, Guérardel Y et al. Structure elucidation of NeuAc, NeuGc and Kdn-containing O-glycans released from Triturus alpestris oviductal mucins. Characterization of the poly LacdiNAc sequence: HSO3(4)(GalNAc $\beta 1$ -4GlcNAc $\beta 1-3) 1-3$ GalNAc $\beta 1-4(G l c N A c \beta 1-3) 0-1$ GlcNAc $\beta 1-$ -6GalNAc-ol. Glycoconj J. 2006;23:377-399.

10. Arranz SE, Albertali IE, Cabada MO. Bufo arenarum egg jelly coat: purification and characterization of two highly glycosylated proteins. Biochem. J. 1997;323:307-312

11. Kawai $Y$ and Anno K. Glycopeptides from the egg jelly coat of the toad Bufo vulgaris. Biochim Biophysica Acta. 1975;381:195-202.

12. Steinke JH and Benson jr DG. The structure and polysaccharide cytochemistry of the jelly envelopes of the egg of the frog, Rana pipiens. J Morph. 1970;130:57-66.

13. Mozingo NM and Hedrick JL. Distribution of lectin binding sites in Xenopus laevis egg jelly. Dev Biol. 1999;210:428-39.

14. Okimura M, Watanabe A, Onitake K. Organization of carbohydrate components in the egg-jelly layers of the newt, Cynops pyrrhogaster. Zool Sci. 2001;18:909-918.

15. Larabell CA and Chandler DE. The extracellular matrix of Xenopus laevis eggs: a quick-freeze, deep-etch analysis of its modification at fertilization. J Cell Biol. 1988;107:731-741.

16. Watanabe A and Onitake K. The Urodele egg-coat as the apparatus adapted for the internal fertilization. Zool Sci. 2002;19:1341-1347.

17. Hedrick JL. Anuran and pig egg zona pellucida glycoproteins in fertilization and early development. Int J Dev Biol. 2008;52:683-701.

18. Salthe SN and Mecham JS. Reproduction and courtship patterns. In: Lofts B, ed. Physiology of the Amphibia. Vol. 2. New York: Academic Press; 1974:309-521.

19. Pinder AW and Friet FC. Oxygen transport in egg masses of the amphibians Rana sylvatica and Ambystoma maculatum: convection, diffusion and oxygen production by algae. J exp Biol. 1994;197:17-30.

20. Räsänen K, Laurila A, Merilä J. Geographic variation in acid stress tolerance of the moor frog, Rana arvalis. II. Adaptive maternal effects. Evolution. 2003;57:363-371.

21. Marquis O, Millery A, Guittonneau S, Miaud C. Toxicity of PAHs and jelly protection of eggs in the common frog Rana temporaria. Amph.-Rept. 2006;27:472-475.

22. Gomez-Mestre I, Touchon JC, Warkentin KM. Amphibian embryo and parental defenses and a larval predator reduce egg mortality from water mold. Ecology. 2006;87:2570-2581. 
23. Edginton AN, Rouleau C, Stephenson GR, Boermans HJ. 2,4-D butoxyethyl ester kinetics in embryos of Xenopus laevis: the role of the embryonic jelly coat in reducing chemical absorption. Arch Environ Contam Toxicol. 2007; 52:113-120.

24. Greulich K, Hoque E, Pflugmacher S. Uptake, metabolism, and effects on detoxication enzymes of isoproturon in spawn and tadpoles of amphibians. Ecotoxicol. Environ. Saf. 2002; 52:256-266.

25. Greulich K, Pflugmacher S. Uptake and effects on detoxication enzymes of cypermethrin in embryos and tadpoles of amphibians. Arch Environ Contam Toxicol. 2004;47: 489-495.

26. Räsänen K, Laurila A, Merilä J. Geographic variation in acid stress tolerance of the moor frog, Rana arvalis. II. Adaptive maternal effects. Evolution. 2003;57:363-371.

27. Krapf D, Vidal M, Arranz SE, Cabada MO. Characterization and biological properties of L-HGP, a glycoprotein from the amphibian oviduct with acrosome-stabilizing effects. Biol Cell. 2006;98:403-413.

28. Adams CK. Threat of Saprolegnia to southeastern amphibians. Southeastern Partners in Amphibian and Reptile Conservation, Disease, Pathogens and Parasites Task Team, Information Sheet n. 6; 2009.

29. Bernanke J, Köhler HR. The impact of environmental chemicals on wildlife vertebrates. Rev Environ Contam Toxicol. 2009;198:1-47.

30. Canestrelli D, Cimmaruta R, Costantini V, Nascetti G. Genetic diversity and phylogeography of the Apennine yellowbellied toad Bombina pachypus, with implications for conservation. Mol Ecol. 2006;15:3741-3754.

31. McManus J. Histological and histochemical uses of periodic acid. Stain Technol. 1948;23:99-108.

32. Mowry R, Winkler CH. The coloration of acid carbohydrates of bacteria and fungi in tissue sections with special reference to capsules of Cryptococcus neoformans, Pneumococci and Staphylococci. Am J Pathol. 1956;32:628-629.

33. Downs F, Herp A, Moschera J, Pigman W. Beta-elimination and reactions and some applications of dimethylsulphoxide on submaxillary glycoproteins. Biochem Biophys Acta. 1973;328:182-192.

34. Finne J, Krusius T. Preparation and fractionation of glycopeptides. Methods Enzymol. 1982;83:269-277.

35. Gallagher JT, Morris A, Dexter TM. Identification of two binding sites for wheat-germ agglutinin on polylactosaminetype oligosaccharides. Biochemical J. 1985;231:115-122.

36. Bhattacharyya L, Haraldsson M, Brewer CF. Precipitation of galactose-specific lectins by complex-type oligosaccharides and glycopeptides: studies with lectins from Ricinus communis (Agglutinin I), Erythrina indica, Erythrina arborescens, Abrus precatorius (Agglutinin), and Glycine max (Soybean). Biochemistry. 1988;27:1034-1041.

37. Hammarström S and Kabat EA. Studies on specificity and binding properties of the blood group A reactive hemagglutinin from Helix pomatia. Biochemistry. 1971; 10:1684-1692.

38. Baker DA, Sughii S, Kabat EA, Ratcliffe RM, Hermentin P, Lemieux RU. Immunochemical studies on the combining sites of Forssman hapten reactive hemagglutinins from Dolichos biflorus, Helix pomatia and Wistaria floribunda. Biochemistry. 1983;22:2741-2750.

39. Lotan R and Sharon N. Peanut (Arachis hypogaea) agglutinin. Methods Enzymol. 1978;50:361-367.

40. Debray H, Montreuil J. Aleuria aurantia agglutinin. A new isolation procedure and further study of its specificity towards various glycopeptides and oligosaccharides. Carbohydr Res. 1989;185:15-26.

41. Sughii S, Kabat EA, Baer HH. Further immunochemical studies on the combining sites of Lotus tetragonolobus and Ulex europaeus I and II lectins. Carbohydr Res. 1982;99:99-101.

42. Debray H, Decout D, Strecker G, Spik G, Montreuil J. Specificity of 12 lectins towards oligosaccharides and glycopeptides related to N-glycosylproteins. Eur J Biochem. 1981;17:41-55.

43. Graham RC, Karnowsky MJ. The early stages of absorption of injected peroxidise in the proximal tubules of mouse kidney: ultrastructural cytochemistry by a new technique. Adv Carbohydr Chem Biochem. 1966;35:127-131.

44. Liquori GE, Scillitani G, Mastrodonato M, Ferri D. Histochemical investigations on the secretory cells in the oesophagogastric tract of the Eurasian green toad, Bufo viridis. Histochem J. 2002;34:517-524.

45. Liquori GE, Mastrodonato M, Zizza S, Ferri D. Glycoconjugate histochemistry of the digestive tract of Triturus carnifex (Amphibia, Caudata). J Mol Histol. 2007;38:191-199.

46. Mastrodonato M, Calamita G, Rossi R, Scillitani G, Liquori GE, Ferri D. Expression of $\mathrm{H}^{+} \mathrm{K}^{+}$ATPase and glycopattern analysis in the gastric glands of Rana esculenta. $J$ Histochem Cytochem. 2009;57:215-225.

47. Reynolds ES. The use of lead citrate at high $\mathrm{pH}$ as an electron-opaque stain in electron microscopy. J Cell Biol. 1963; 17:208-212.

48. Hedrick JL, Nishihara T. Structure and function of the extracellular matrix of anuran eggs. J Electron Microsc Tech. 1991;17:319-335.

49. Ippolito E, Pedrini VA, Pedrini-Mille A. Histochemical properties of cartilage proteoglycans. J Histochem Cytochem. 1983; 31:53-61.

50. Hofman S, Spolsky C, Uzzell T, Cogalniceanu D, Babik W, Szymura JM. Phylogeography of the fire-bellied toads Bombina: independent Pleistocene histories inferred from mitochondrial genomes. Mol Ecol. 2007;16:2301-2316.

51. Mariano MI, De Martin MG, Pisano E. Morphological modifications of oocyte vitelline envelope from Bufo arenarum during different functional states. Dev Growth Differ. 1984; 26:33-42.

52. Vo LH, Yen TY, Macher BA, Hedrick JL. Identification of the ZPC oligosaccharide ligand involved in sperm binding and the glycan structures of Xenopus laevis vitelline envelope glycoproteins. Biol Reprod. 2003;69:1822-1830.

53. Freeman SB. A study of the jelly envelopes surrounding the egg of the amphibian, Xenopus laevis. Biol Bull. 1968; 135: 501-513.

54. Pereda J. Etude histochimique de la distribution des sialomucines dans l'oviducte et les gangues muqueuses des ovocytes de Rana pipiens. Comportement dans l'eau des differentes gangues. J Embryol Exp Morph. 1970;24:1-12.

55. Shivers CA, James JM. Morphology and histochemistry of the oviduct and egg-jelly layers in the frog, Rana pipiens. Anat Rec. 1970;166:541-555.

56. Schauer R, Kamerling JP. Chemistry, biochemistry and biology of sialic acids. In: Montreuil J, Vliegenthart J FG, Schachter H, eds. Glycoproteins II Amsterdam: Elsevier Science; 1997:243-402.

57. Berner NJ, Ingermann RL. Role of sialic acid in exogenous protein accumulation and water retention by the egg jelly of the salamander Ambystoma macrodactylum. J. Exp. Zool. 1990;256:38-43.

58. Mengerink KJ, Vacquier VD. Glycobiology of sperm-egg interactions in deuterostomes. Glycobiology. 2001: 11: 37R-43R. 
59. Brooks SA, Dwek MV, Schumacher U. Functional and molecular glycobiology. Oxford: Bios Scientific Publishers Ltd; 2002.

60. Bonnell BS, Keller SH, Vacquier VD, Chandler DE. The sea urchin egg jelly coat consists of globular glycoproteins bound to a fibrous fucan superstructure. Dev Biol. 1994;162: 313-324.

61. Wallace JL and Granger DN. The cellular and molecular basis of gastric mucosal defense. FASEB J. 1996;10:731-740.

62. Hounsell EF, Davies MJ, Renouf DV. O-linked protein glycosylation structure and function. Glycoconjugate $J$ 1996; 13:19-26.
63. Barbieri FD, del Pino EJ. Jelly coats and diffusible factor in Anuran fertilization. Arch. Biol (Liege). 1975;86:311-321

64. Al-Anzi B, Chandler DE. A sperm chemoattractant is released from Xenopus egg jelly during spawning. Dev. Biol. 1998;198:366-375.

65. Arranz SE, Cabada MO. Diffusible highly glycosylated protein from Bufo arenarum egg-jelly coat: Biological activity. Mol. Reprod. Dev. 2000;56:392-400.

66. Kang HS, Gye MC, Kim MK. Effects of endosulfan on survival and development of Bombina orientalis (Boulenger) embryos. Bull Environ Contam Toxicol. 2008;81:262-265.

Submitted: 14 September, 2010 Accepted after reviews: 30 January, 2011 